Yayın Geliş Tarihi: 30.10 .2017

Yayına Kabul Tarihi: 11.07.2018

Online Yayın Tarihi: 12.11.2018

http://dx.doi.org/10.16953/deusosbil.347861
Dokuz Eylül Üniversitesi

Sosyal Bilimler Enstitüsü Dergisi

Cilt: 20, Say1: 3, Y11: 2018, Sayfa: 443-459

ISSN: 1302-3284 E-ISSN: 1308-0911

Araştırma Makalesi

\title{
SAĞLIK KAYGISI İLE İLIŞKIILİ FAKTÖRLER: SAĞLIK KAYGISINDA BAĞLANMANIN ROLÜ VAR MIDIR?
}

Elçin YORULMAZ*

$\ddot{O} z$

Gülay DİRIK ${ }^{* *}$

Bu çalışmada sağglık kaygısı ile ilişskili faktörler özellikle de bağlanma stillerinin sağlık kaygısı ile iliş̧kisinin incelenmesi amaçlanmıştır. Bu amacı gerçekleştirmek için sağllk kayglsı, hipokondriazis, hastallk kaygısı ve bağlanma anahtar kelimeleri ile değişik veri tabanlarl kullanilarak (Web of Science, EBSCHOHost, Elsevier Science Direct, PsycARTICLES, PsycINFO, SocINDEX, ULAKBIM Türk Tip Dizini/Sosyal Bilimler Dizini) son 20 yll içerisinde yapılan araştırmalar taranmışstr. Taranan araştırmalarda incelenen boyutlar dikkate alınarak, sağllk kaygısı ve bağlanma stilleri arasındaki ilişki sağllk kaygısı ve hipokondriazis, sağllk kaygısının bilişsel ve kişilerarası modeli, sağlık kaygısl ve bağlanma ve onay arayıcılık bașlikları altında ele alınmıștır. Öncelikle, sağlık kaygısı ile ilgili genel bilgilere yer verilmiștir. Sonrasında, sağllk kaygısını daha iyi açıklamak için gelişstirilmişs olan bilişsel modele ve kişilerarası modele değinilmiştir. Ardından, kişilerarası modelin temelinde yer alan bağlanma kuramina ve sağllk kaygısı ile bağlanma stilleri ilișkisine dair yapılan araștırmalara yer verilmiștir. Sağllk kaygısının güvensiz bağlanmanın bir yansiması olduğu, özellikle kaygılı bağlanma ile ilişkili olduğu belirtilmiştir. Son olarak, iki model kapsamında da onay arayıcılı̆̆a yer verilmişstir. Sonuç bölümünde ise, araştırmalar ile ilgili genel bir özet verilmiş ve gelecek çalışmalar için önerilerde bulunulmuştur.

Anahtar Kelimeler: Sağllk Kaygısı, Hipokondriazis, Hastalık Kaygısı Bozukluğu, Bağlanma Stilleri, Onay Arayıcılık.

Bu makale için önerilen kaynak gösterimi (APA 6. Sürüm):

Yorulmaz, E. \& Dirik, G. (2018). Sağlık kaygısı ile ilişkili faktörler: Sağlık kaygısında bağlanmanın rolü var mıdır?. Dokuz Eylül Üniversitesi Sosyal Bilimler Enstitüsü Dergisi, 20 (3), 443-459.

* Araş. Gör., Dokuz Eylül Üniversitesi, Edebiyat Fakültesi, Uygulamalı Psikoloji Anabilim Dal1, ORCID: 0000-0001-8353-0952, elcin.ayranci@deu.edu.tr

** Prof. Dr., Dokuz Eylül Üniversitesi, Edebiyat Fakültesi, Uygulamalı Psikoloji Anabilim Dal1, ORCID: 0000-0002-5748-9180, gulay.dirik@deu.edu.tr 


\title{
FACTORS RELATED WITH HEALTH ANXIETY: IS THERE A ROLE OF ATTACHMENT IN HEALTH ANXIETY?
}

\begin{abstract}
In this study, it is aimed to examine the factors related with health anxiety especially the relationship between health anxiety and attachment styles. In order to achieve this purpose, researches done in the last 20 years have been searched using different databases (Web of Science, EBSCHOHost, Elsevier Science Direct, PsycARTICLES, PsycINFO, SocINDEX, ULAKBIM Turkish Medical Directory / Social Sciences Directory) with the key words of health anxiety, hypochondriasis, illness anxiety, and attachment. Taking into account the dimensions examined in the surveys, the relationship between health anxiety and attachment styles was examined under the headings of health anxiety and hypochondriasis, cognitive and interpersonal model of health anxiety, health anxiety and attachment, and approval seeking. First of all, general information on health anxiety is included. Later, cognitive and interpersonal models developed to better explain health anxiety were mentioned. After that, the theory of attachment found at the base of the interpersonal model, and research on the relationship between health anxiety and attachment styles has been included. It has been noted that health anxiety are a reflection of insecure attachment, particularly associated with anxious attachment. Lastly, reassurance seeking within the scope of the two models, was also included. In the conclusion section, a general summary of researches has been given and suggestions for future studies have been made.
\end{abstract}

Keywords: Health Anxiety, Hypochondriasis, Illness Anxiety Disorder, Attachment Styles, Reassurance Seeking.

\section{SAĞLIK KAYGISI VE HIPOKONDRİAZİS}

Sağlık kaygısı bireylerin bir hastalığının olduğu ya da hastalığa yakalanacakları inançlarına dair sürekli korku ya da kaygılarını içermektedir (Taylor ve Asmundson, 2004). Sağlı kaygısı DSM-IV'te (Diagnostic and Statistical Manual of Mental Disorders, Fourth Edition) hipokondriazis olarak adlandırılan hastalıkta yoğun olarak yaşanmaktadır. Sağlı kaygıs1 hipokondriazisin duygusal boyutunu oluşturmaktadır. Fakat hipokondriazisin kaçınma ve onay arayıcılık gibi davranışsal boyutu ile "hastalık inancı", "hastalık kuşkusu" ya da "hastalık kanaati" olarak anılan bilişsel boyutu da bulunmaktadır. Bir başka deyişle, hipokondriazis duygusal boyut olarak sağlık kaygısını içeren bir rahatsızlıktır (Starcevic ve Noyes, 2014). Önceki yıllarda hipokondriazisin bir başka rahatsızlığa genellikle depresyona ikincil olarak geliştiği düşünülmekteydi. (Kenyon, 1964). Daha sonraki yıllarda ise, sağlıkla ilişkili kaygıların temel problem olabileceği, duygusal belirtilerin ikincil olabileceği ifade edilmiştir (Bianchi, 1971) ve hipokondriazis DSM-IV'te yer almıştır (APA, 2000).

Hipokondriazis DSM-IV'te somatoform bozukluklar kategorisinde yer almasına rağmen, hipokondriazisin bir somatoform bozukluğu mu yoksa bir kayg1 bozukluğu mu olduğu halen tartış1lmaktadır (Salkovskis ve Warwick, 1986; 
Warwick ve Salkovskis, 1990). Hipokondriazis DSM-IV'te “vücut semptomlarının yanlış yorumlanmasına bağlı olarak, kişinin ciddi bir hastalığı olacağı korkusunu ya da ciddi bir hastalığı olduğu düşüncesini taşıyıp durması" ve "yeterli tıbbi değerlendirme yapılmasına ve güvence verilmesine karşın bu düşünceler sürüp gitmektedir" maddeleri ile karakterizedir (APA, 2000). DSM V'te (Diagnostic and Statistical Manual of Mental Disorders, Fifth Edition) ise hipokondriazis tanıs1 yer almamakta, bu tanı yerine 'bedensel belirti bozuklukları' ve 'hastalık kaygısı bozukluğu' olarak iki tanı bulunmaktadır (APA, 2013). Hipokondriazis tanısı alan bireylerin \%75'inin bedensel belirti bozukluğu tanısı, \%25'inin ise hastalık kaygısı tanısı almasının beklendiği belirtilmektedir (Starcevic ve Noyes, 2014). DSM V'te yer alan hastalık kaygısı bozukluğunda ise "ağır bir hastalığı olduğunu ya da olacağını düşünüp durma", "bedensel belirti yoktur ya da varsa bile ağır değildir", "sağlıkla ilgili yüksek düzeyde bir kaygı vardır ve kişi, kişisel sağlık durumuyla ilgili olarak kolaylıkla korkuya kapılır" ve "kişinin sağlıkla ilgili davranışlarında aşırılıklar görülür ya da uygunsuz bir kaçınma içindedir" kriterleri yer almaktadır. Hastalık kaygısı bozukluğunda bakım arayan ve bakımdan kaçan olmak üzere iki alt tip bulunmaktadır. Bakım arayan tür, sık sık doktora gitmeyi ya da sağlık taraması yaptırmayı kapsarken, bakımdan kaçan tür ise sağlık bakımına seyrek olarak başvurmaktadır (APA, 2013).

Sağlık kaygısının yaygınlığı pek çok çalışmada incelenmiştir. Sağlık kaygısının yaşam boyu görülme sıklığı yaklaşık \%5,7 olarak belirlenirken, çalışmanın yapıldığı dönemde katılımcıların \%3,4'ünün sağlık kaygısı kriterlerini karşıladığı belirtilmiştir (Sunderland vd., 2013). Amerikan Psikiyatri Birliği tarafından sağlık kaygısının genel popülasyonun yaklaşık \%10'unu etkilediği belirtilirken (2000), DSM-IV'ün bütün kriterleri dikkate alınarak yapılan bir çalışmada hipokondriazis yaygınlığının \%0,05 - \%0,4 arasında değiştiği sonucuna ulaşılmıştır (Bleichhardt ve Hiller, 2007; Looper ve Kirmayer, 2001; Martin ve Jacobi, 2006). Fakat DSM-V gibi daha geniş tanı kriterlerine göre ise bu oranın \%1'e çıktığı belirtilmektedir (Starcevic ve Noyes, 2014). Ayrıca, APA'nın 2000 yılındaki çalışması ile benzer şekilde, yaygınlığın tanı kriterinin sağlanmasının dışına çıkarak incelendiği çalışmalardan birinde sağlığa yönelik kaygıların \%2 ile \%10 arasında değiştiği sonucuna ulaşılmıştır (Starcevic ve Noyes, 2014). Araştırmalar da yaygınlığın tanı kriterlerinin dışına çıkarılarak incelenmesini destekler niteliktedir. Bu araştırmalarda sağlık kaygısının olumsuz etkilerinin klinik popülasyon ile sinırlı olmadığ 1 belirtilmekle beraber (Hadjistavropoulos ve Lawrance, 2007), hafif şiddetteki sağlık kaygısının bile yüksek sağlık hizmeti kullanımı (Abramowitz vd., 2007; Barsky vd., 2005; Ferguson, 2004) ve düşük yaşam kalitesi ile ilişkili olduğu ve ağır şiddetteki sağlık kaygısı için de bir risk faktörü oluşturduğu sonucuna ulaşılmıştır (Ferguson, 2004). Yüksek sağlık hizmeti kullanımından dolayı, sağlık kaygısı sosyal yük ve artan sağlık harcamaları ve yüksek iş görememezlik ile ilişkili bulunmuştur (Abramowitz vd., 2007; Barsky vd., 2001; Creed ve Barsky, 2004; Mykletun vd., 2009). Hipokondriazis ayrıca majör depresif bozukluk, madde kullanım bozuklukları (Noyes vd., 1994), kaygı 
bozuklukları (Escobar vd., 1998; Fink vd., 2004) ve kişilik bozuklukları (Barsky, 1992; Fallon vd., 2012; Sakai vd., 2010) gibi pek çok rahatsızlık ile komorbid (birlikte) olarak görülmektedir.

Hafif düzeyinin bile önemli etkilerinin olduğu ve pek çok rahatsızlık ile birlikte görülebilen sağlık kaygısı için risk faktörlerini belirlemek önem taşımaktadır. Risk faktörleri, genetik, erken dönem yaşantılar, kişilik ve bağlanma olarak belirlenmiştir (Starcevic ve Noyes, 2014). Hipokondriazis'in genetik riskini incelemek için yapılmış birkaç ikiz çalışması mevcuttur (DiLalla vd., 1996). Taylor ve arkadaşları tarafindan yapılan bir çalışmada ise Hastalık Tutumları Ölçeği'nin alt ölçeklerinde genetiğin açıkladığı varyans \%13 ile \%37 arasında değişirken, çevre daha büyük bir varyans açıklamaktadır (2006). Yapılan diğer çalışmalar da genetiğin sağlık kaygısı ve hipokondriazis gelişiminde önemli bir rolünün olduğu, fakat çevresel faktörlerin daha önemli olduğu sonucuna ulaşmıştır (Asmundson vd., 2010; Torgersen, 1986). Ayrıca, 2,000 Norveçli ikiz katılımcı ile gerçekleştirilen çalışmada somatoform bozuklukların depresyon, kaygı bozuklukları ve kişilik bozuklukları ile (Kendler vd., 2011), Avustralyalı 2489 ikiz ile gerçekleştirilen bir başka çalışmada ise, hipokondriazisin panik bozukluk ve obsesif-kompülsif bozukluk ile genetik ortaklıklarının olduğu tespit edilmiştir (Lopez-Sola vd., 2013). Özetle, aile ve ikiz çalışmaları net bir genetik etkiyi ortaya koyamamışlardır fakat hipokondriazisin diğer hastalıklarla olan olası genetik ilişkisini ortaya koymuşlardır (Starcevic ve Noyes, 2014). Genetik risklerin yanı sıra kişilik de bir risk faktörü olarak belirlenmiştir. Yapılan çalışmalarda hipokondriazis pek çok kişilik bozukluğu ile ilişkili (Fallon vd., 2012; Sakai vd., 2010) bulunduğu gibi pek çok kişilik özelliği ile de ilişkili bulunmuştur. Örneğin, hipokondriazis tanısı olanların hipokondriazis tanıs1 olmayan katılımc1lara göre yüksek nörotisizim (Birley vd., 2006; Calboli vd., 2010; Hollifield vd., 1999; Noyes vd., 2003) ve düşük dışadönüklük puanına sahip oldukları belirlenmiştir (Hollifield vd., 1999). Yapılan bir boylamsal çalışmada da hastalık kaygısındaki azalma duygusal olgunluk ve sorumluluk ile ilişkili bulunmuştur (Ferguson, 2004). Bir diğer risk faktörü erken dönem yaşantılar olarak belirlenmiştir. Hipokondriazis hastalarında daha fazla çocukluk dönemi hastalığı (Fernandez vd., 2005; Noyes vd., 2002; Weck vd., 2014), travmatik cinsel birleşme, fiziksel şiddet ve ebeveynler arası çatışma rapor edilmiştir (Barsky vd., 1994). Üniversite öğrencileri ile yapılan bir başka çalışmada da çocukluk dönemindeki fiziksel ve cinsel istismar yetişkinlikteki somatizasyon, hipokondriazis ve sağlık hizmeti kullanımı ile ilişkili bulunmuştur (Bellet, 2003; Salmon ve Calderbank, 1996). Fakat, çocukluk dönemindeki kötü muamelenin hipokondriazis ile ilişkili olmadığını belirleyen bir çalışma da mevcuttur (Bailer vd., 2014). Ayrıca, hastalık kaygısı olan bireylerin büyük bir kısmının çok hasta ya da yaralanmış bir arkadaşa ya da aile üyesine sahip oldukları belirlenmiştir (Noyes vd., 2005). Hasta olan ebeveynin ölümünün de sağlı kaygısını yordadığı tespit edilmiştir (Alberts ve Hadjistavropoulos, 2014). Son olarak, bağlanma da bir risk faktörü olarak belirlenmiştir. Bağlanma yaşamın erken dönemlerinde çocuk ile bakım veren (genellikle anne) arasındaki etkileşim 
sonucunda oluşan ve kişinin gelecekteki ilişkilerini etkileyen bir örüntüdür. Bağlanma stilleri ile hastalık kaygısı pek çok farklı örneklem ile incelenmiştir (Wearden vd., 2006; Noyes vd., 2003; Schmidt vd., 2002). Bağlanma stilleri aynı zamanda yardım arama davranışını anlamlandırmada da kullanışlı bir çerçeve olarak önerilmiştir (Stuart ve Noyes, 1999). Kaygılı bağlanma stili sergileyen kişilerin daha fazla sağlık hizmetinden yararlanması ve daha fazla onay araması beklenirken, kaçıngan bağlanma stiline sahip olanların uygun bakımı yok sayacağı düşünülmektedir (Maunder ve Hunter, 2001). Yapılan bir başka çalışmada da kaygılı bağlanmanın tıbbi bakım ile ilgili daha az memnuniyet ve güvence rapor ettiği bu durumun da hem terapötik ilişkiyi hem de hipokondriyak eğilimi etkilediği belirtilmektedir (Noyes vd., 2003).

Literatür bulguları bağlanma örüntüsünün sağlık kaygısı ile oldukça ilişkili bir faktör olduğunu göstermektedir. Bu nedenle, bu çalışmada önemli bir risk faktörü olan bağlanma stillerinin sağlık kaygısı ile olan ilişkisini incelemek amacıyla, sağlık kaygısı, hipokondriazis, hastalık kaygısı ve bağlanma anahtar kelimeleri ile değişik veri tabanları kullanılarak (Web of Science, EBSCHOHost, Elsevier Science Direct, PsycARTICLES, PsycINFO, SocINDEX, ULAKBİM Türk Tıp Dizini/Sosyal Bilimler Dizini) son 20 y1l içerisinde yapılan araştırmalar taranmıştır. Ardından taranan araştırmalarda incelenen boyutlar dikkate alınarak, sağlık kaygısı ve bağlanma stilleri arasındaki ilişki sağlık kaygısı ve hipokondriazis, sağlık kaygısının bilişsel ve kişilerarası modeli, sağlık kaygısı ve bağlanma ve onay arayıcılık başlıkları altında ele alınmıştır.

\section{SAĞLIK KAYGISININ BİLIŞSEL MODELİ}

Sağlık kaygısına yönelik oluşturulan modellerden biri olan sağl1k kaygısının bilişsel modeli Beck'in bilişsel modelinden (1976) ve anksiyete modelinden (Beck vd., 1985; Clark, 1999) yararlanılarak oluşturulmuştur (Salkovskis vd., 1993; Warwick ve Salkovskis, 1990). Bu modele göre, tehdit edici durumlar sağlıkla ilişkili işlevsiz inançlara ve varsayımlara yol açmaktadır (Warwick ve Salkovskis, 1990). Bu inançlar da belirsiz beden duyumları ya da hastalık ya da ölüm gibi kritik durumlarla tetiklenirken, bu inançların bireylerin hastalıkla olan geçmiş deneyimlerinin ya da ciddi bir hastalığa tanık olmalarının (örn. ebeveynin kanser olması) sonucunda oluştuğu belirtilmektedir (Salkovskis ve Warwick, 2001). Sağlık kaygısını sürdüren 4 faktör bulunmaktadır. Bunlar, bilişsel, duygusal, fizyolojik ve davranışsal faktörlerdir. Bilişsel faktörler seçici dikkat, ruminasyon, bilişsel hatalar olarak belirlenirken, duygusal faktörler kayg1, depresyon ve korku olarak belirlenmiştir. Ek olarak, fizyolojik faktörler ise kalp atımındaki, uyku durumundaki ve bağırsak fonksiyonlarındaki değişimler olarak ifade edilmiştir. Son olarak, davranışsal faktörler; tekrarlı kontrol, kaçınma davranışı, güvenlik davranışı ve onay arayıcılıktır. Davranışsal faktörlerden biri olan onay arayıcılık pek çok çalışmada incelenmiştir (Salkovskis ve Warwick, 1986; Weardon vd., 2006) ve partnere ya da aile üyelerine semptomları sormak, 
diğerlerine sürekli semptomlarından bahsetmek, doktora gitmek, inceleme ya da test rica etmek ve kendi kendine tanı koyabilmek ya da ciddi hastalıkları devre dışı bırakmak için tıbbi makaleleri ve kitapları okumak şekillerinde olabilmektedir (Wells, 1997). Günümüzde onay arayıcılık ise internetten bilgi almak şeklinde olabilmektedir, bu da siberkondri (cyberchondria) olarak adlandırılmaktadır (Doherty-Torstrick vd., 2016; Lagoe ve Atkin, 2015; te Poel vd., 2016). Bilişsel davranışçı terapilerin etkililiğine dair yapılan çalışmalarda ise bilişsel davranışçı terapinin sıkıntıyı ve psikolojik semptomları azalttığı fakat fiziksel semptomları azaltmadığı bulgusuna ulaşılmıştır (Allen vd., 2006; Barsky ve Ahern, 2004; Clark vd., 1998). Bu anlamda, bilişsel ve davranışsal süreçlerin çokça çalışıldığ (Taylor ve Asmundson, 2004) fakat kişilerarası süreçlerin ihmal edildiği belirtilmiştir (Longley vd., 2005) ve yapılan çalışmalarda da kişilerarası süreçlerin rolünün önemli olduğu belirlenmiştir (Jordan vd., 2015; Noyes vd., 2003; Williams vd., 2010). Çünkü sağlık kaygısının önemli bir yönünün doktordan ya da terapistten onay almak olduğu belirtilmektedir. Onay almadaki yetersizliğin de hastanın verilen bakımın yeterli olduğunu kabul etmemesinden kaynaklandığı ifade edilmiştir. $\mathrm{Bu}$ yetersizliğin sıkıntı yarattığı ve genellikle hasta, klinisyen ve hastanın destek ağı arasındaki iletişim probleminin sonucunda oluştuğu belirtilmiştir (Starcevic ve Noyes, 2014). Bunun sonucunda da hipokondriazisin ve sağlık kaygısının kişilerarası modeli ortaya konmuştur (Noyes vd., 2003; Stuart ve Noyes, 1999; Williams vd., 2010).

\section{SAĞLIK KAYGISININ KISŞILLERARASI MODELİ}

Sağlık kaygısının kişilerarası modeline göre, sağlık kaygısı güvensiz bağlanmanın patolojik bir gösterimidir. Bir başka deyişle, açıklanamayan tıbbi semptomların ve ilişkili kaygının ve bakım arayışının kaygılı ve güvensiz ebeveynçocuk bağlanmasından kaynaklandığını öne sürülmektedir. Güvensiz bağlanmanın da olumsuz ebeveynlik stilleri ve olumsuz erken deneyimler neticesinde oluştuğu belirtilmektedir (Noyes vd., 2003). Bu olumsuz erken deneyimlerden birinin de ebeveynin hasta olmasının olabileceği belirtilmiş olup, ebeveyn hastalığının sağlık kaygısı gelişimine yol açabileceği belirtilmiştir. Bu görüş yapılan çalışmalarla da desteklenmiştir (Eifert ve Forsyth, 1996; Hotopf vd., 1999).

Bağlanma ve sağlık kaygısı arasındaki ilişki kişilerarası model tarafindan onay arayıcılık üzerinden açıklanmıştır. Noyes ve arkadaşları (2003) sağlık kaygısında görülen onay arayıcılık davranışını, güvensiz bağlanmayı ve sağlık problemlerindeki kaygıyı başkalarından bakım sağlayarak azaltma girişimi olarak açıklamışlardır. Fakat sağlık kaygısı olan bireylerde güvensiz bağlanma kronik olduğundan tekrarlayan onay arayıcılık işe yaramamaktadır. Tekrarlı onay arayıcılık hastalık kaygısı olan kişiyi rahatlatmadığı gibi başkaları ile çatışmaya neden olarak dışlanmaya neden olmaktadır. Çatışma ve dışlanma ise güvensiz bağlanmayı desteklemekte ve arttırmaktadır. Hem güvensiz bağlanma hem de başkaları tarafından dışlanmanın getirdiği sıkıntı sağlık problemleri ile ilişkili 
kaygıyı arttırmaktadır. Bu kaygının artması onay arayıcılığa o da dışlanmaya (Waldinger vd., 2006), dışlanma da tekrar kaygiya (Macdonald ve Kingsbury, 2006) neden olmaktadır. Yani, bu anlamda bir kısır döngü oluşmakta (akt. Sherry vd., 2014) ve işlevsiz bir hale gelmektedir (Puri ve Dimsdale, 2011). Kişilerarası modelin sağlık kaygısı için geçerli bir model olduğunu destekleyen çalışmalar mevcuttur (örn. Birnie vd., 2013).

Güvensiz bağlanma, sağlık kaygısının kişilerarası modeline göre sağlık kaygısının temelini oluşturmaktadır. Bağlanma kuramına göre ise erken dönemdeki özellikle ebeveynler ile olan yakın ilişkiler bireyin sonraki etkileşimlerini ve diğerleri ile olan ilişkilerini etkilemektedir (Bowlby, 1969; 1988). Temel bakım veren kişiyle kurulan bağlanma ilişkisinin kalitesi zaman içerisinde çocuğun hem kendisiyle hem de başkalarıyla ilgili "içsel çalışan modeller" olarak isimlendirilen zihinsel tasarımlar geliştirmesine yol açar (Bowlby, 1988). Zihinsel tasarımlar kişinin sosyal çevreden gelen tepkileri ne kadar tutarlı ve güvenilir olarak değerlendirdiğine ve kişinin kendisini ne derece sevilmeye değer bulduğuna bağlı olarak olumlu ya da olumsuz olurlar. Algılamadaki bu farklılıklar da bağlanma stilini oluştururlar (Bowlby, 1973; Main vd., 1985). Bağlanma stilleri son yıllarda güvenli, korkulu, saplantılı ve kayıtsız olmak üzere dörtlü bağlanma modeli kapsamında ele alınmakla birlikte (Bartholomew ve Horowitz, 1991), Ainsworth ve arkadaşlarının (1978) ortaya koydukları üç tip bağlanma stili de kullanılmaktadır. Bu üç tip bağlanma stili ise, güvenli, kaygıl1/kararsız ya da kaygılı dirençli ve kaçınandır (akt. Sümer ve Güngör, 1999). Dörtlü bağlanma modelinden saplantılı bağlanmanın Ainsworth ve arkadaşları (1978) tarafından ortaya konmuş kaygılı/kararsız bağlanma ile örtüşen taraflarının olduğu ve Bartholomew ve Horowitz'in (1991) kaygıl1/kararsız bağlanmayı kayıtsız ve korkulu olmak üzere ikiye ayırdığı belirtilmektedir (akt. Wearden vd., 2006).

Önceki araştırmalarda bağlanma açısından kategorik bir yaklaşım kabul edilse de, daha yeni dönemdeki çalışmalar bağlanma için boyutsal bir yaklaşımı benimsemektedirler (Fraley ve Shaver, 2000). Bağlanmaya yönelik amprik geçerliliği olan boyutsal bir model, güvensiz bağlanmanın kaygılı bağlanma ve kaçıngan bağlanma olmak üzere iki boyutunun olduğunu göstermektedir (Fraley ve Shaver, 2000). Kaygılı bağlanmada kişiler önemli diğerleri tarafindan terk edileceklerine ya da red edileceklerine dair sürekli bir korku taşırlarken, kaçıngan bağlanmada diğerlerine bağlı kalmaktan dolayı rahatsızlık hissetme ve yakın ilişkilerden uzaklaşma eğilimi görülmektedir (Fraley ve Shaver, 2000). Kaygılı ve kaçıngan bağlanma puanlarının düşük olmasının güvenli bağlanmayı, yüksek olmasının ise güvensiz bağlanmayı yansıttığı belirtilmektedir. Mikulincer ve Shaver'e göre (2003) güvensiz bağlanma stilleri birey bir tehditle karşılaştı̆̆ında belirli bir kişilerarası davranış ve duygu düzenleme örüntüsüne yol açmaktadır. Kaygılı bağlanma etkin bir strateji kullanılmasına yol açarken, kaçıngan bağlanma edilgen bir strateji kullanılmasina neden olmaktadır (akt. Anagnostopoulos ve Botse, 2016). Bu çalışmalarda da olduğu gibi bağlanmanın kavramsallaştırması ve 
ölçülmesi çalışmadan çalışmaya farklılık göstermektedir (Brennan vd., 1998; Fraley ve Shaver, 2000; Fraley ve Spieker, 2003).

\section{SAĞLIK KAYGISI VE BAĞLANMA}

Kişilerarası model, sağlı kaygısı ile belirli bir bağlanma stilini eşleştirmese de (Noyes vd., 2003), pek çok faktör sağlık kaygısı ile kaygılı bağlanmanın ilişkili olabileceğini göstermektedir. Kaygılı bağlanma stili sergileyen bireylerin stres durumlarında yalnız baş edemediklerini belirttikleri ve diğerlerinin desteğine yönelik endişelerinin olduğu tespit edilmiştir (Fraley ve Shaver, 2000). $\mathrm{Bu}$ sebeple de sağlıklarına yönelik endişelerinin olması gibi stresli deneyimleri sırasında yardım aradıkları belirtilmiştir (Ciechanowski vd., 2002). Aksine, kaçıngan bağlanma stili sergileyen bireylerin diğerlerini ulaşılmaz gördükleri ve stres zamanlarında kendilerini diğerlerinden uzaklaştırdıkları ifade edilmiştir. Ek olarak, kaçıngan bağlanmada bireylerin kaygılarını ifade etme ve sağlık bakımı kullanma ihtimallerinin daha düşük olduğu belirtilmektedir (Feeney ve Ryan, 1994). Yapılan çalışmalar da bu faktörleri destekler niteliktedir. Yani, sağlık kaygısı kaygılı bağlanma stili ile ilişkili bulunurken (Birnie vd., 2013; Jordan vd., 2015; Schmidt vd., 2002; Sherry vd., 2014), kaçıngan bağlanma ile sağlık kaygısı ilişsili bulunmamıştır (Sherry vd., 2014). Fakat yapılan bir başka çalışmada analizlere çocukluk dönemi kötüye kullanımı, duygu düzenleme, depresyon, kaygı duyarlılığ1 ve nörotisizim gibi değişkenler eklendiğinde kaygılı bağlanma stilinin sağlık kaygısının yordayıcısı olmadığı bulunmuştur (Reiser, 2013). Ek olarak, Bartholomew ve Horowitz'in (1991) dörtlü bağlanma modeli temel alınarak yapılan çalışmalarda saplantılı bağlanmanın hipokondriazis ile ilişkisinin olduğu (Bellet, 2003; Wearden vd., 2006), bu ilişkide de onay arayıcıllı̆ı̀n aracı rolünün olduğu bulunmuştur (Wearden vd., 2006). Noyes ve arkadaşlarının yaptıkları bir başka çalışmada ise hipokondriyak belirtilerin bütün güvensiz bağlanma stilleri ile özellikle korkulu bağlanma stili ile ilişkili olduğu sonucuna ulaşılmıştır (2003).

Bağlanma stilleri ve sağlık kaygısına yönelik yapılan çalışmalarda hastalık kaygısının genellikle kaygılı bağlanma ile ilişkili olduğu, kaçıngan bağlanma ile ilişkili olmadığ sonucuna ulaşılmıştır (Sherry vd., 2014). Ancak, ebeveynin hasta olmasının bağlanma stilleri ile hastalık kaygısı ilişkisi açısından önemli bir değişken olabileceği belirtilmiştir. Yapılan bir çalışmada ebeveyni hasta olan bireylerde hem kaygılı hem de kaçıngan bağlanma sağlık kaygısının bir yordayıcısı olarak bulunmuştur (Alberts ve Hadjistavropoulos, 2014). Alberts ve Hadjistavropoulos'un (2014) yaptıkları bu çalışma ile sağlık kaygısı için başlı başına bir risk faktörü olan ebeveynin hasta olması durumunun diğer çalışmalarda bir risk faktörü olarak ortaya konmamış olan kaçıngan bağlanmanın etkisini arttırdığı sonucunun çıkarılabileceği düşünülmektedir. 
$\underline{\text { Sağglk Kaygısı ile İlișkili... }}$

DEU Journal of GSSS, Vol: 20, Issue: 3

\section{ONAY ARAYICILIK}

Bilişsel model için davranışsal bir sürdürücü faktör olarak ele alınan onay arayıcılık (Salkovskis vd., 1993; Warwick ve Salkovskis, 1990), bazı çalışmalarda sağlık kaygısının bir boyutu olarak ele alınmıştır (Longley vd., 2005). Longley ve arkadaşlarına göre sağlık kaygısının dışlanma, onay arayıcılık, içine çekme ve kaygı olmak üzere 4 boyutu bulunmaktadır. Onay arayıcılık sağlık kaygısının davranışsal boyutu olarak belirlenmiş olup, sağlık endişelerine yönelik sosyal destek alma eğilimi olarak tanımlanmıştır. Kaygılı bağlanma ile onay arayıcılık arasında bir ilişki bulunmazken, kaçıngan bağlanma ile onay arayıcılık arasında negatif bir ilişki bulunmaktadır (Birnie vd., 2013). Kaygılı bağlanma ve onay arayıcılık arasında bir ilişki bulunmamasına ölçülmemiş düzenleyici bir değişkenin neden olabileceğine yönelik bir açıklama getirmişlerdir. Bu değişkenin hastalıklar ile erken dönemdeki yaşantılar olabileceği, hastalıklarla olan erken dönemdeki yaşantıların ya da inançların ya da davranışların kaygılı bağlanma stiline sahip bireyleri onay aramaya yönelttiği ifade edilmiştir (Watt vd., 2008). Yapılan bir başka çalışmada da onay arayıcılık ile kaygılı bağlanma arasında pozitif ilişki bulunurken, kaçıngan bağlanma ile arasında negatif ilişki olduğu sonucuna ulaşılmıştır (Anagnostopoulos ve Botse, 2016). Ayrıca, Bartholomew ve Horowitz'in (1991) dörtlü bağlanma modeli temel alınarak yapılan bir çalışmada saplantılı ve korkulu bağlanmanın onay arayıcılık ile ilişkisinin olduğu sonucuna ulaşılmıştır (Wearden vd., 2006).

\section{SONUÇ}

Bu çalışmanın amacı sağlık kaygısı ile bağlanma stilleri arasındaki ilişkinin incelenmesidir. $\mathrm{Bu}$ amacı gerçekleştirmek için sağlık kaygısı, hipokondriazis, hastalık kaygısı ve bağlanma anahtar kelimeleri ile değişik veri tabanları kullanılarak (Web of Science, EBSCHOHost, Elsevier Science Direct, PsycARTICLES, PsycINFO, SocINDEX, ULAKBIM Türk Tıp Dizini/Sosyal Bilimler Dizini) son 20 yıl içerisinde yapılan araştırmalar taranmıştır. Ardından taranan araştırmalarda incelenen boyutlar dikkate alınarak, bağlanmanın sağlık kaygısı ile olan ilişkisi sağlı kaygısı ve hipokondriazis, sağlı kaygısının bilişsel ve kişilerarası modeli, sağlık kaygısı ve bağlanma ve son olarak onay arayıcılık başlıkları altında incelenmiştir.

Sağlık kaygısını anlamlandırmak için çeşitli modeller önerilmiştir. $\mathrm{Bu}$ modellerden biri bilişsel model iken (Salkovskis vd., 1993; Warwick ve Salkovskis, 1990), diğeri kişilerarası modeldir (Noyes vd., 2003). Bu iki modelin de geçmiş yaşantılar ile ilişkilendirdiği bir taraf mevcuttur. Bilişsel modelin temelinde işlevsiz inançlar ve varsayımlar vardır ve bu inançlar ile varsayımların geçmiş deneyimlerden temel aldığı vurgulanır (Salkovskis ve Warwick, 2001). Kişilerarası modelin ise temelinde güvensiz bağlanma vardır ve güvensiz bağlanmanın da geçmiş deneyimler neticesinde oluştuğu belirtilmektedir (Noyes 
vd., 2003). Iki model için de benzer olan bir diğer nokta onay arayıcılıktır. Bilişsel model onay arayıcılığı sürdürücü bir faktör olarak ele almaktadır (Salkovskis ve Warwick, 1986; Weardon vd., 2006). Kişilerarası model ise güvensiz bağlanma ve sağlık problemlerine dair kaygıyı azaltma girişimi olarak çerçevelendirmiştir (Noyes vd., 2003). Bilişsel model kişilerarası ilişkileri ele almadığı için eleştirilmiş ve kişilerarası model öne sürülmüştür. Kişilerarası modelin temelinde güvensiz bağlanma vardır ve kişilerarası model bağlanma ve hastalık kaygısı ilişkisini onay arayıcılık üzerinden açıklamıştır. Onay arayıcılığın bireyi rahatlatmadığına ve başkaları ile çatışmaya neden olduğuna değinilmiştir. Çatışmanın dışlanmaya neden olarak kaygıyı tekrar arttırdığı, bunun da bir kısır döngüye yol açtığ belirtilmiştir (Noyes vd., 2003). Bağlanma stilleri açısından incelendiğinde hastalık kaygısının kaçıngan bağlanmaya kıyasla kaygılı bağlanma ile ilişkisinin daha fazla olduğu belirtilmiştir (örn. Sherry vd., 2014). Bu çalışma kapsamında incelenen araştırmalar da kaygılı bağlanma ile hastalık kaygısının ilişkisini daha çok desteklerken bir yandan da bağlanma stillerinin farklı şekillerde kavramsallaştırılmış ya da ölçülmüş olmaları (Brennan vd., 1998; Fraley ve Shaver, 2000; 2003), yapılan çalışmalar arasındaki karşılaştırmayı ya da çalışmaları bütünleştirmeyi de zorlaştırmaktadır. Yapılan bir inceleme çalışmasında da psikosomatik araştırmalarda kullanılan 29 bağlanma ölçeğinin olduğu belirlenmiştir. $\mathrm{Bu}$ ölçeklerinin 11 tanesinin güçlü psikometrik özelliklere sahip olduğu belirtilmiştir (Ravitz vd., 2010). Gelecek çalışmalarda bu ölçeklere ait özelliklerin ve çalışmada neye odaklanıldığının dikkate alınması önem taşımaktadır.

Sosyal destek azlığ belirlenmiş̧ir (Noyes vd., 2004). Longley ve arkadaşlarına (2005) göre onay arayıcılık sağlık endişelerine yönelik sosyal destek alma eğilimi olarak tanımlanmıştır. Bir başka deyişle, bu bireylerin sosyal destek azlığını onay arama davranışı ile telafi etmeye çalıştıkları düşünülebilir. Fakat bu yol da sosyal desteği sağlamak açısından işlevsel görünmemektedir çünkü bireylerin dışlanmasına yol açmaktadır (Noyes vd., 2003). Gelecek çalışmalarda, sağlık kaygısı yüksek olan bireylere sosyal desteği nasıl alacakları ve nasıl yorumlayacaklarına dair eğitimlerin verilmesinin belki de onay arayıcılığı azaltabileceği düşünülmektedir, bu da dolaylı yoldan sağlık kaygısını azaltmaya yönelik bir girişim olabilecektir. Erken evre meme kanseri olan kadınlarla yapılan bir çalışmada hem destekleyici olmayan sosyal etkileşimlerin hem de algılanan sosyal desteğin sağlık kaygısı ile ilişkili bulunması da bu öneriyi destekler niteliktedir. Bu çalışmada sosyal desteğin bir onay arama aracı olabileceği belirtilmekle beraber, burada ölçümlenen onay aramanın sağlık kaygısındaki gibi işlevsiz onay arama olmadığı vurgulanmıştır (Jones vd., 2012).

Yapılan çalışmalar sonucunda kaçıngan bağlanmaya kıyasla kaygılı bağlanmanın sağlık kaygısı ile daha güçlü ilişkiye sahip olduğu sonucuna ulaşılmıştır (Sherry vd., 2014). Bununla ilgili olarak da gelecek çalışmalarda kaçıngan bağlanmanın diğer kaygı bozuklukları ile ilişkilerinin incelenmesi 
gerektiği, belki de sosyal fobi gibi kişilerarası geri çekilme özellikleri olan kaygı türlerinin kaçıngan bağlanma ile ilişkili olabileceği belirtilmiştir (Sherry vd., 2014). Bir başka deyişle, kaçıngan bağlanma sağlı kaygısı ile güçlü ilişkili bulunmamıştır fakat diğer kaygı bozuklukları ile ilişkisi gelecek çalışmalarda incelenmelidir.

\section{KAYNAKÇA}

Abramowitz, J. S., Deacon, B. J. \& Valentiner, D. P. (2007). The Short Health Anxiety Inventory: Psychometric properties and construct validity in a nonclinical sample. Cognitive Therapy and Research, 31 (6): 871-883.

Alberts, N. M. \& Hadjistavropoulos, H. D. (2014). Parental illness, attachment dimensions, and health beliefs: testing the cognitive-behavioural and interpersonal models of health anxiety. Anxiety, Stress \& Coping, 27 (2): 216-228.

Allen, L. A., Woolfolk, R. L., Escobar, J. I., Gara, M. A. \& Hamer, R. M. (2006). Cognitive-behavioral therapy for somatization disorder: a randomized controlled trial. Archives of Internal Medicine, 166 (14): 1512-1518.

Amerikan Psikiyatri Birliği (APA) (2000). DSM-IV tanı ölçütleri başvuru el kitabı. E. Köroğlu (Çev.). Ankara: Hekimler Yayın Birliği.

Amerikan Psikiyatri Birliği (APA) (2013). DSM-V tanı ölçütleri başvuru el kitabı. E. Köroğlu (Çev.). Ankara: Hekimler Yayın Birliği.

Anagnostopoulos, F. \& Botse, T. (2016). Exploring the role of neuroticism and insecure attachment in health anxiety, safety-seeking behavior engagement, and medical services utilization: A study based on an extended interpersonal model of health anxiety. SAGE Open, 6 (2): 1-13.

Asmundson, G. J., Abramowitz, J. S., Richter, A. A. \& Whedon, M. (2010). Health anxiety: current perspectives and future directions. Current Psychiatry Reports, 12 (4): 306-312.

Bailer, J., Witthöft, M., Wagner, H., Mier, D., Diener, C. \& Rist, F. (2014). Childhood maltreatment is associated with depression but not with hypochondriasis in later life. Journal of Psychosomatic Research, 77 (2): 104-108.

Barsky, A. J. (1992). Hypochondriasis and obsessive compulsive disorder. Psychiatric Clinics of North America, 15 (4): 791-801.

Barsky, A. J. \& Ahern, D. K. (2004). Cognitive behavior therapy for hypochondriasis. Journal of the American Medical Association, 291 (12): 14641470 . 
Barsky, A. J., Ettner, S. L., Horsky, J. \& Bates, D. W. (2001). Resource utilization of patients with hypochondriacal health anxiety and somatization. Medical Care, 39 (7): 705-715.

Barsky, A. J., Orav, E. J. \& Bates, D. W. (2005). Somatization increases medical utilization and costs independent of psychiatric and medical comorbidity. Archives of General Psychiatry, 62 (8): 903-910.

Barsky, A. J., Wool, C., Barnett, M. C. \& Cleary, P. D. (1994). Histories of childhood trauma in adult hypochondriacal patients. American Journal of Psychiatry, 151 (3): 397-397.

Bartholomew, K. \& Horowitz, L. (1991). Attachment styles among young adults: A test of a four category model. Journal of Personality and Social Psychology, 61 (2): 226-241.

Bellet, B. L. (2003). An investigation of personality factors in somatization and hypochondriacal tendencies: A study of coping style, attachment, alexithymia and empathy. Yayınlanmamış Doktora Tezi. Adelphi University, The Institute of Advanced Psychological Studies, New York.

Bianchi, G. N. (1971). The origins of disease phobia. Australia and New Zealand Journal of Psychiatry, 5 (4): 241-257.

Birley, A. J., Gillespie, N. A., Heath, A. C., Sullivan, P. F., Boomsma, D. I. \& Martin, N. G. (2006). Heritability and nineteen-year stability of long and short EPQ-R Neuroticism scales. Personality and Individual Differences, 40 (4): 737747.

Birnie, K. A., Sherry, S. B., Doucette, S., Sherry, D. L., Hadjistavropoulos, H. D. \& Stewart, S. H. (2013). The Interpersonal Model of Health Anxiety: Testing predicted paths and model specificity. Personality and Individual Differences, 54 (7): 856-861.

Bleichhardt, G. \& Hiller, W. (2007). Hypochondriasis and health anxiety in the German population. British Journal of Health Psychology, 12 (4): 511-523.

Bowlby, J. (1969). Attachment and loss (Vol. 1): Attachment. New York, NY: Basic Books.

Bowlby, J. (1973). Attachment and loss: Separation, anxiety and anger. New York: Basic Books.

Bowlby, J. (1988). A secure base: Clinical applications of attachment theory. London, England: Routledge.

Brennan, K. A., Clark, C. L. \& Shaver, P. R. (1998). Self-report measurement of adult romantic attachment: An integrative overview. J. A. Simpson \& W. S. Rholes (Der.) Attachment theory and close relationships: İçinde 46-76. New York, NY: Guilford Press. 
Calboli, F. C., Tozzi, F., Galwey, N. W., Antoniades, A., Mooser, V., Preisig, M., ... \& Muglia, P. (2010). A genome-wide association study of neuroticism in a population-based sample. PloS One, 5 (7): e11504.

Ciechanowski, P. S., Walker, E. A., Katon, W. J. \& Russo, J. E. (2002). Attachment theory: a model for health care utilization and somatization. Psychosomatic Medicine, 64 (4): 660-667.

Clark, D. M., Salkovskis, P. M., Hackmann, A., Wells, A., Fennell, M., Ludgate, J., ... \& Gelder, M. (1998). Two psychological treatments for hypochondriasis. A randomised controlled trial. The British Journal of Psychiatry, 173 (3): 218-225.

Creed, F. \& Barsky, A. (2004). A systematic review of the epidemiology of somatisation disorder and hypochondriasis. Journal of Psychosomatic Research, 56 (4): 391-408.

DiLalla, D. L., Carey, G., Gottesman, I. I. \& Bouchard Jr, T. J. (1996). Heritability of MMPI personality indicators of psychopathology in twins reared apart. Journal of Abnormal Psychology, 105 (4): 491-499.

Doherty-Torstrick, E. R., Walton, K. E. \& Fallon, B. A. (2016). Cyberchondria: Parsing Health Anxiety From Online Behavior. Psychosomatics, 57 (4): 390-400.

Eifert, G. H. \& Forsyth, J. P. (1996). Heart-focused and general illness fears in relation to parental medical history and separation experiences. Behaviour Research and Therapy, 34 (9): 735-739.

Escobar, J. I., Gara, M., Waitzkin, H., Silver, R. C., Holman, A. \& Compton, W. (1998). DSM-IV hypochondriasis in primary care. General Hospital Psychiatry, 20: 155-159.

Fallon, B. A., Harper, K. M., Landa, A., Pavlicova, M., Schneier, F. R., Carson, A., ... \& Liebowitz, M. R. (2012). Personality disorders in hypochondriasis: prevalence and comparison with two anxiety disorders. Psychosomatics, 53 (6): 566-574.

Feeney, J. A. \& Ryan, S. M. (1994). Attachment style and affect regulation: relationships with health behavior and family experiences of illness in a student sample. Health Psychology, 13 (4): 334-345.

Ferguson, E. (2004). Personality as a predictor of hypochondriacal concerns. Journal of Psychosomatic Research, 56 (3): 307-312.

Fernandez, C., Fernandez, R. \& Amigo, D. I. (2005). Characteristics and one-year follow-up of primary care patients with health anxiety. Primary Care and Community Psychiatry, 10 (3), 89-101. 
Fink, P., Ornbol, E., Toft, T., Sparle, K. C., Frostholm, L. \& Olesen, F. (2004). A new, empirically established hypochondriasis diagnosis. American Journal of Psychiatry, 161 (9): 1680-1691.

Fraley, R. C. \& Shaver, P. R. (2000). Adult romantic attachment: Theoretical developments, emerging controversies, and unanswered questions. Review of General Psychology, 4 (2): 132-154.

Fraley, R. C. \& Spieker, S. J. (2003). Are infant attachment patterns continuously or categorically distributed? A taxometric analysis of strange situation behavior. Developmental Psychology, 39 (3): 387-404.

Hadjistavropoulos, H. \& Lawrence, B. (2007). Does anxiety about health influence eating patterns and shape-related body checking among females? Personality and Individual Differences, 43 (2): 319-328.

Hollifield, M., Tuttle, L., Paine, S. \& Kellner, R. (1999). Hypochondriasis and somatization related to personality and attitudes toward self. Psychosomatics, 40 (5): 387-395.

Hotopf, M., Mayou, R., Wadsworth, M. \& Wesseley, S. (1999). Childhood risk factors for adults with medically unexplained symptoms: Results from a national birth cohort study. American Journal of Psychiatry, 156 (11): 1796-1800.

Jones, S. L., Hadjistavropoulos, H. D. \& Sherry, S. B. (2012). Health anxiety in women with early-stage breast cancer: What is the relationship to social support?. Canadian Journal of Behavioural Science/Revue Canadienne Des Sciences Du Comportement, 44 (2): 108-116.

Jordan, K. D., Williams, P. G. \& Smith, T. W. (2015). Interpersonal Distinctions among Hypochondriacal Trait Components: Styles, Goals, Vulnerabilities, and Perceptions of Health Care Providers. Journal of Social and Clinical Psychology, 34 (6): 459-475.

Kendler, K. S., Aggen, S. H., Knudsen, G. P., Røysamb, E., Neale, M. C. \& Reichborn-Kjennerud, T. (2011). The structure of genetic and environmental risk factors for syndromal and subsyndromal common DSM-IV axis I and all axis II disorders. American Journal of Psychiatry, 168 (1): 29-39.

Kenyon, F. E. (1964). Hypochondriasis: A clinical study. British Journal of Psychiatry, 110 (467): 478-488.

Lagoe, C. \& Atkin, D. (2015). Health anxiety in the digital age: An exploration of psychological determinants of online health information seeking. Computers in Human Behavior, 52: 484-491.

Longley, S. L., Watson, D. \& Noyes Jr, R. (2005). Assessment of the hypochondriasis domain: the multidimensional inventory of hypochondriacal traits (MIHT). Psychological Assessment, 17 (1): 3-14. 
Looper, K. J. \& Kirmayer, L. J. (2001). Hypochondriacal concerns in a community population. Psychological Medicine, 31 (4): 577-584.

Lopez-Sola, C., Alonso, P., Fontenelle, L. F., Cuadras, D., Menchón, J. M. \& Harrison, B. J. (2013). P. 4. b. 005 Hypochondriasis, panic and obsessivecompulsive symptoms: genetic overlap in a twin-based population sample. European Neuropsychopharmacology, 23 (2): S514.

Macdonald, G. \& Kingsbury, R. (2006). Does physical pain augment anxious attachment? Journal of Social and Personal Relationships, 23 (2): 291304.

Main, M., Kaplan, N. \& Cassidy, J. (1985). Security in infancy, childhood, and adulthood: A move to the level of representation. Monographs of the Society for Research in Child Development, 50 (1\&2, Serial No. 209): 66-104.

Martin, A. \& Jacobi, F. (2006). Features of hypochondriasis and illness worry in the general population in Germany. Psychosomatic Medicine, 68 (5): 770-777.

Maunder, R. G. \& Hunter, J. J. (2001). Attachment and psychosomatic medicine: developmental contributions to stress and disease. Psychosomatic Medicine, 63 (4): 556-567.

Mykletun, A., Heradstveit, O., Eriksen, K., Glozier, N., Overland, S., Maland, J. G. \& Wilhelmsen, I. (2009). Health anxiety and disability pension award: The HUSK Study. Psychosomatic Medicine, 71 (3): 353-360.

Noyes, R., Kathol, R. G., Fisher, M. M., Phillips, B. M., Suelzer, M. T. \& Woodman, C. L. (1994). Psychiatric comorbidity among patients with hypochondriasis. General Hospital Psychiatry, 16 (2): 78-87.

Noyes, R., Carney, C. P., Hillis, S. L., Jones, L.E. \& Langbehn, D. R. (2005). Prevalence and correlates of illness worry in the general population. Psychosomatics, 46 (6): 529-539.

Noyes Jr, R., Stuart, S. P., Langbehn, D. R., Happel, R. L., Longley, S. L., Muller, B. A. \& Yagla, S. J. (2003). Test of an interpersonal model of hypochondriasis. Psychosomatic Medicine, 65 (2): 292-300.

Noyes, R., Stuart, S., Langbehn, D. R., Happel, R. L., Longley, S. L. \& Yagla, S. J. (2002). Childhood antecedents of hypochondriasis. Psychosomatics, 43 (4): 282-289.

Noyes, R., Watson, D. B., Carney, C. P., Letuchy, E. M., Peloso, P. M., Black, D. W. \& Doebbeling, B. N. (2004). Risk factors for hypochondriacal concerns in a sample of military veterans. Journal of Psychosomatic Research, 57 (6): 529-539. 
Puri, P. \& Dimsdale, J. (2011). Health care utilization and poor reassurance. Psychiatric Clinics of North America, 34 (3): 525-544.

Ravitz, P., Maunder, R., Hunter, J., Sthankiya, B. \& Lancee, W. (2010). Adult attachment measures: A 25-year review. Journal of Psychosomatic Research, 69 (4): 419-432.

Reiser, S. J. (2013). Childhood abuse and health anxiety: The roles of attachment and emotion regulation. Yayınlanmamıs Doktora Tezi. University of Regina, Faculty of Graduate Studies and Research, Alberta.

Sakai, R., Nestoriuc, Y., Nolido, N. V. \& Barsky, A. J. (2010). The prevalence of personality disorders in hypochondriasis. The Journal of Clinical Psychiatry, 71 (1): 41-47.

Salkovskis, P. M. \& Warwick, H. M. C. (1986). Morbid preoccupations, health anxiety and reassurance: A cognitive behavioural approach to hypochondriasis. Behaviour Research and Therapy, 24 (5): 597-602.

Salkovskis, P. M. \& Warwick, H. (2001). Making sense of hypochondriasis: a cognitive theory of health anxiety. G. Asmundson, S. Taylor \& B. J. Cox (Der.) Health Anxiety: Clinical and Research Perspectives on Hypochondriasis and Related Conditions. İçinde 46-64. New York: Wiley.

Salkovskis, P. M., Warwick, H. M., \& Clark, D. M. (1993). Panic disorder and hypochondriasis. Advances in Behavior Research and Therapy, 15 (1): 23-48.

Salmon, P. \& Calderbank, S. (1996). The relationship of childhood physical and sexual abuse to adult illness behavior. Journal of Psychosomatic Research, 40 (3): 329-336.

Schmidt, S., Strauss, B. \& Braehler, E. (2002). Subjective physical complaints and hypochondriacal features from an attachment theoretical perspective. Psychology and Psychotherapy: Theory, Research and Practice, 75 (3): 313-332.

Sherry, D. L., Sherry, S. B., Vincent, N. A., Stewart, S. H., Hadjistavropoulos, H. D., Doucette, S. \& Hartling, N. (2014). Anxious attachment and emotional instability interact to predict health anxiety: An extension of the interpersonal model of health anxiety. Personality and Individual Differences, 56: 89-94.

Starcevic, V. \& Noyes, R. (2014). Hypochondriasis and Health Anxiety: A guide for Clinicians. New York: Oxford University Press.

Stuart, S., \& Noyes, R. (1999). Attachment and interpersonal communication in somatization. Psychosomatics, 40 (1): 34-43. 
Sunderland, M., Newby, J. M. \& Andrews, G. (2013). Health anxiety in Australia: prevalence, comorbidity, disability and service use. The British Journal of Psychiatry, 202 (1): 56-61.

Sümer, N. \& Güngör, D. (1999). Yetişkin bağlanma stilleri ölçeklerinin Türk örneklemi üzerinde psikometrik değerlendirmesi ve kültürlerarası bir karş1laştırma. Türk Psikoloji Dergisi, 14 (43): 71-106.

Taylor, S. \& Asmundson, G. (2004). Treating health anxiety: A cognitivebehavioralapproach. New York, NY: Guilford.

Taylor, S., Thordarson, D. S., Jang, K. L. \& Asmundson, G. J. (2006). Genetic and environmental origins of health anxiety: A twin study. World Psychiatry, 5 (1): 47-50.

te Poel, F., Baumgartner, S. E., Hartmann, T. \& Tanis, M. (2016). The curious case of cyberchondria: A longitudinal study on the reciprocal relationship between health anxiety and online health information seeking. Journal of Anxiety Disorders, 43: 32-40.

Torgersen, S. (1986). Genetics of somatoform disorders. Archives of General Psychiatry, 43 (5): 502-505.

Waldinger, R., Schulz, M., Barsky, A. \& Ahern, D. (2006). Mapping the road from childhood trauma to adult somatization: The role of attachment. Psychosomatic Medicine, 68 (1): 129-135.

Warwick, H. M. C. \& Salkovskis, P. M. (1990). Hypochondriasis. Behaviour Research and Therapy, 28 (2): 105-117.

Watt, M., O'Connor, R., Stewart, S., Moon, E. \& Terry, L. (2008). Specificity of childhood learning experiences in relation to anxiety sensitivity and illness/ injury sensitivity. Journal of Cognitive Psychotherapy, 22 (2): 128-142.

Wearden, A., Perryman, K. \& Ward, V. (2006). Adult attachment, reassurance seeking and hypochondriacal concerns in college students. Journal of Health Psychology, 11 (6): 877-886.

Weck, F., Neng, J. M., Göller, K. \& Müller-Marbach, A. M. (2014). Previous experiences with illness and traumatic experiences: a specific risk factor for hypochondriasis? Psychosomatics, 55 (4): 362-371.

Wells, A. (1997). Cognitive therapy of anxiety disorders: A practice manual and conceptual guide. John Wiley \& Sons.

Williams, P. G., Smith, T. W., \& Jordan, K. D. (2010). Health anxiety and hypochondriasis: Interpersonal extensions of the cognitive-behavioral perspective. G. Beck (Der.) Interpersonal processes in the anxiety disorders: İçinde 261-284. Washington, DC: American Psychological Association. 